\title{
17. Challenges and dilemmas in the provision of social services
}

\author{
Anneli Anttonen
}

\section{INTRODUCTION: THE GROWING IMPORTANCE OF SOCIAL SERVICES}

'Social services' are a social policy field with a rapidly growing political and theoretical importance. They belong to a larger family of welfare services comprising care, health, housing, education, employment and personal social services. These services enhance human welfare and the overall well-being of people, but in different ways and through different mechanisms. Some welfare services are universal in the sense that they are designed for all people, such as primary education, and there are no needs tests used. Other services are universal but granted only after an individual assessment of needs, such as healthcare and certain care services for older people. Other social services still are strictly means-tested (Anttonen et al., 2012).

Social services provide immaterial and material resources for citizens to cope with changed life situations, such as becoming disabled or chronically ill, the parent of a child or a family caregiver. They constitute a very heterogeneous cluster of publicly funded and regulated services and benefits that are closely linked to the life-cycle risks people encounter during their life course from the cradle to the grave (Jensen, 2010). Care services for older people are typically needed to cope with frailty or disability in old age. They cover a wide range of functions, from home help to transportation and personal bodily services.

Care services differ from mainstream welfare services - those of universal childcare, education and healthcare services (Bode, in this volume) - in one important dimension: they are often unfocused and many-sided. They might include practical, emotional and physical help. Care services for older people are thus necessarily complex by definition. There is often also a complementarity dimension to be taken into account: a person needing care and help might receive services from municipal providers and informal help from his/her family; such an individual might additionally use his/her 
own money to purchase help. These different sources of help usually complement each other, but they can also be regarded as substitutes. Formal services have partly become a substitute for families in providing help, but there is also a strong trend in many countries towards re-familiarisation (e.g. Leibetseder et al., in this volume).

Another difference with mainstream welfare services is a lack of universality: social care services for older people are in practice always needstested, and often means tests are also used. As a result, access to these services is limited to poor, older people and those whose care needs are very extensive and who have no other available sources of aid.

Diversity and complexity mean that although in this context the notion of social services refers only to publicly funded and regulated services, the producer of the service might vary across policy fields and countries: there are service providers from local/regional/central governments, as well as from civil society associations, voluntary agencies and large and small private for-profit companies. In some countries, caregivers within the household have also become publicly subsidised care providers.

There are a number of reasons why care services for older people in their variety and diversity serve as a very good object to evaluate the development, dynamics and dilemmas of social services in contemporary European welfare states. There also is a need to better understand the main characteristics of social services in contemporary European societies.

In this book, broad attention is paid to trends and changes, transformations and tensions in social service policies and practices. Some chapters paint a broad picture of recent changes in social service landscapes and rationalities (Martinelli, Chapter 1, in this volume; Bode, in this volume), while others concentrate on a more limited aspect of change, for instance de-institutionalisation (Kröger and Bagnato; Kubalčíková et al; Deusdad, Lev et al., in this volume) and marketisation (Anttonen and Karsio, in this volume). This chapter, in turn, approaches social services - with specific reference to care for older people - from three angles. First, social services are discussed as benefits that are linked to 'life-course' welfare, as opposed to 'occupational welfare'. Second, care service provisions for older people are put into perspective with regard to universalism or the lack of it. Third, complexity and complementarity are taken into consideration as attributes that might influence the overall value and status of these services. Finally, conclusions are drawn on the basis of this examination. 


\section{SOCIAL SERVICES, LIFE-COURSE WELFARE AND THE LOW STATUS OF CARE SERVICES FOR OLDER PEOPLE}

Social services enhance the human welfare of citizens (residents within one country) irrespective of their position in the labour market. They are needed during the entire life course and are closely linked to life-cycle risks (Jensen, 2010). There are social risks more directly attached to the individual's position in the labour market, such as retirement. These lifecycle risks are typically covered by more or less compulsory social insurance schemes paid for by employers and/or by employees and protected by national or federal legislation. Typically, beneficiaries have clearly defined social rights to occupational welfare benefits that are often earningsrelated or income-tested. Life-cycle risks touch however the individual's and/or household's welfare also in cases of maternity, childhood, disability, old age, and other vulnerabilities related, for example, to ethnicity. These risks are something people meet both as insiders and outsiders in their relation to the labour market. Services and benefits attached to life-course welfare are typically covered by tax revenues and are provided by local governments, even in the absence of explicit social rights.

Unrecognised life-cycle risks increase vulnerabilities and might lead to severe neglect in meeting very basic needs, such as nutrition or shelter, and a loss of autonomy. This is currently the case with migrants in many European countries, as even the very basic social needs of many asylum seekers are not presently met. Social services are needed in very different life situations to safeguard a decent standard of living, to integrate people into society and to compensate for losses or shortages in capabilities and resources.

Earlier in history and even today, social services were and are needed by the most vulnerable groups of a society; the historical trend has, however, been towards the generalisation and normalisation (Anttonen et al., 2003; Bode, in this volume) of access to these services. Life-cycle risks involve all people and families, but only a few households have the capacity to arrange or purchase all the aid and help needed for instance in old age on the market if care needs are very extensive and 24-hour care and attendance is required for long periods. This example helps to clarify the universalisation of life-cycle risks. It can be argued that today, vulnerabilities touch the masses instead of just the marginal groups in society.

Although social services have become more 'normal' and they are used by much larger parts of the population than before, there still are hierarchies between different sets of welfare services and between occupational and life-course welfare. In the social policy literature, there is much 
more attention paid to 'occupational welfare', for instance, pensions and labour protection legislation. However, 'life-course welfare' is becoming more important due to the ageing of societies, prolonged and high youth unemployment, increased poverty among children and huge increases in immigration into Europe. A considerable proportion of people stay outside the (formal) labour market for shorter or longer periods, and not only because they are children or old, disabled or chronically ill. There are benefits of the first tier and benefits of the second tier: 'occupational welfare' tends to have a higher status compared to 'life-course welfare', and mainstream welfare services are more highly valued than most care services. Nonetheless, new polarisations are emerging not only between occupational and life-course benefits, but also within occupational welfare policies, since labour markets have become precarious and unpredictable (Seeleib-Kaiser, 2008). This development could mean that social services will gain a much stronger foothold in Europe. Already now, social risks covering unemployment, poverty, ill-health and old age in Europe add up to roughly 50 per cent of government spending (Hemerijck, 2013, p. 1).

Jensen (2010, p. 404) talks about a 'forgotten half' in the sense that occupational welfare is much more extensively studied compared to social services. The volume of social services has however significantly expanded in the last twenty years in Europe. Between 1990 and 2010 there was a steady increase in family services (Ferragina and Seeleib-Kaiser, 2015). Even after the financial crisis of 2008, spending most particularly on childcare has continued to increase in many European countries, while for instance the Netherlands and Southern and Eastern European countries have seen cuts (Bode, in this volume; Bouget et al., 2015). Expenditure on care for older people is reported to have remained fairly stable over this period after two preceding decades of fairly strong growth (Bouget et al., 2015). However, the situation of care services for older people differs greatly from that for children because the starting point was much lower and the share of the oldest older people has grown rapidly. Therefore, this stability means that on a per capita basis, expenditure may have diminished. Some social services, particularly childcare services, are now regarded by politicians as benefits that are expected to increase human capital in the same way as school and healthcare might do. The 'social investment' turn in welfare theorising and European Union policies has actually helped to recognise the productive and active role of social policies (Jenson, 2011). All this means that social services have gained a stronger foothold in research.

Hemerijck (2013, p.33), however, argues that although the volume of social services has expanded in Europe, the average commitment to the 'social service state' is still weak. If the status of a social risk or of the service attached to that risk is weak and steady political backing is lacking, 
social services easily become subject to cuts and austerity policies when resources for welfare spending are reduced. It is often the case - as shown in this book - that care for older people and other social services are at the top of the list when publicly funded services must be cut. In this respect, the notion of the 'forgotten half' or 'forgotten part' of welfare services is true. The status hierarchies are there, despite the overall expansion of social services.

Care-based life-cycle risks are covered very differently in different European countries, and this is most particularly the case with care services for older people. At one end of the spectrum are some Southern and Central-Eastern European countries such as Greece and Poland, where care is understood strictly as a family responsibility. At the other end of the spectrum are the Nordic welfare states and Germany, where care for older people is recognised as a social right of citizens. Ultimately, satisfying the social, medical or cultural needs of citizens by means of social services is always based on the political recognition of the risks people might encounter during their life course. Before a service is made available for individuals, there has to be a political decision about the institutional design through which these services are made accessible and affordable to those needing them.

\section{UNIVERSALISM IN CARE SERVICE PROVISION}

'Universalism' means slightly different things in social services compared to pensions, for instance (Holmlund, 2016). The term refers first of all to inclusion: all are potentially included and all have the right at least to needs assessment. Second, there has to be public funding for service provision and also a public system of regulation and delivery. Third, services should be affordable to all, which means that they have to be subsidised for users by the state or local government. Fourth, the services should be of such a high quality that people in need want to use them.

International comparisons of care service provisions for older people (Anttonen and Sipilä, 1996; Ranci and Pavolini, 2013; Stoy, 2014) reveal that there are surprisingly large national-level differences in the funding, scale, scope and targeting of care services between European countries. The same is true when support for informal care, such as payments to caregivers and recipients, have been compared (Pfau-Effinger and Geissler, 2005). In some countries, for instance in Germany and Austria, there is a national care insurance scheme that covers adults. However, in these countries there are also some conditions that are taken into consideration before benefits are granted. The introduction of care insurance is nonetheless an 
important step taken in the longer history of the modernisation and universalisation of social services (CAP Bode, 2013).

In Northern European countries, service universalism is more advanced than elsewhere, as argued by Vabø and Szebehely (2012). They suggest that service universalism rests on four pillars: accessibility, affordability, attractiveness and flexibility. They also remind us that universal access to services does not automatically guarantee high rates of uptake. Publicly supported social services should be of a high quality so that people are willing and happy to use these services, otherwise they easily become residual, stigmatising or selective services. This is one reason why raw figures (e.g. coverage rates) do not provide enough information. Residential care services, if arranged in large, hospital-like institutions, might carry the labels of stigma and even shame, while places in small, home-like environments are viewed - at least in principle - as attractive and non-stigmatising for service users (Verbeek et al., 2009). Both quality and quantity matter for the evolution of service universalism.

In most European countries, care services for older people are strictly targeted at those who need them the most and have no other means or resources at their disposal. In nearly all countries, these services are granted only after professional assessment procedures, meaning that a needs test is used. Often a means test is also part of the evaluation process, so that only persons with a low income eventually receive care services. This is the case for instance in Greece or Southern Italy, where public care services for older people have remained residual, means-tested and lean: public home care service provisions there are both insufficient and inadequate, and the recent crises have worsened the situation (CAP Vaiou and Siatitsa, 2013; CAP Bagnato et al., 2014).

Southern European countries have had a strong commitment to the family as the primary provider of care, especially for adults. Even so, the 1990s and early 2000s saw some important steps taken towards more extensive public responsibility. In Spain, new social service legislation that could have paved the way towards a Nordic kind of service model was passed in 2006, but due to the 2008 crisis, the reforms were not implemented as planned (CAP Deusdad, 2013). In Greece and Southern Italy, the family model had already entered into crisis in the 1990s, but care remained individualised and within the family sphere due to the availability of informal migrant care workers that families could turn to (CAP Vaiou and Siatitsa, 2013; CAP Bagnato et al., 2014). This again has been a barrier to the development of public services - and vice versa: if there are services for only the most vulnerable and poor people, families are forced to find non-state-based solutions (CAP Pace and Bezzina, 2012). Thus, although care services for older people have become more extensive in the 
last thirty years, contradictory developments have also taken place. The differences between countries are still extensive, which somehow reflects the ambiguous and unstable status of social (care) services.

These examples indicate that while in some countries the development of care services is characterised by increasing universalisation, in some others universalism is still a very weak principle and a distant goal. However, the Nordic care model is also going through some major reorganisations due to the intensive marketisation of service provision (Anttonen and Karsio, in this volume), which has also framed and shaped the restructuring of social services in the United Kingdom (CAP Yeandle, 2014). Some countries that had a strong commitment to family care twenty years ago (Anttonen and Sipilä, 1996) have not redefined this commitment, but there are exceptions. Both some Southern European and post-socialist Central and Eastern European countries have only recently passed social service legislation similar to other European countries. Consequently, these countries are only now taking major steps towards some level of normalisation in their social service systems. A good example in the latter group is the Czech Republic (CAP Kubalčíková and Havlíková, 2013).

Care services at best should reduce the differences in meeting life-cycle risks, irrespective of social class, gender and place of residence. Although legally guaranteed or universal access to services is crucial in social service development, this does not automatically lead to high rates of uptake: services should be of high quality and free-of-charge or strongly subsidised so that everyone can and will want to use them. In some countries, rising service fees and new types of co-funding mechanisms have weakened universalism, despite equal access and assessment. If services can be purchased out of the citizen's own pocket and reimbursed via tax deductions, there is not necessarily an assessment taking place. Thus, people with better economic resources have access to subsidised services even if they are not entitled to municipally governed services. This is the case, for example, in Finland and Sweden. By contrast, low-income households do not benefit from tax deductions, and must thus turn to informal networks if the services provided by formal provision do not meet their needs.

Universalism can be weakened in many different ways. If subsidised service fees are too high for users, universalism starts to lose its significance as a mechanism for the redistribution of collective resources, and exits from the public service system increase. Universalism is not a stand-alone principle but it needs to be protected by other principles such as sufficient funding and quality control (Anttonen et al., 2012). When service systems start to differentiate and there are new mechanisms emerging alongside the old ones, it might become difficult to maintain universalism. There are some signs that marketisation weakens the principle of universalism 
(Béland et al., 2014). In this respect, European countries might be coming together in a sort of 'downward convergence' (see the concluding chapter by Martinelli, in this volume).

\section{COMPLEXITY AND COMPLEMENTARITY: STRENGTH AND WEAKNESS}

Life-course welfare benefits such as social services influence people's lives and choices in many ways and have manifold consequences. Childcare services, which might be educational or social by definition, exemplify this multiplicity very well. The ability of women to enter the labour market depends on the availability of care services, be they formal or informal, publicly or privately produced. Access to these services makes it possible for women to make very important life-course choices, promotes gender equality and provides children opportunities for learning and socialising. The same applies to care services for older people. They are important for working-age adults, most particularly working women, but they also make it possible for older people to continue independent living at home instead of moving into institutions or relying on their partners or family members when needing care. Services also create new jobs, both well-paid and lowpaid, primarily for women and immigrants - this again has many consequences for the overall economy and the employment rate (see Martinelli, Chapter 19, in this volume). To sum up, within democracy social services encourage 'human development, not least in the capacity for exercising self-determination, moral autonomy, and responsibility for one's choices' (Dahl, 1989, p. 311).

While most social services relate to life-cycle risks, they should be defined in a broad and flexible way that takes into account the complexity of needs when we talk about care. Complexity means that there is a large variety of needs to be met: some people need house cleaning and help with personal hygiene once a week, while others need daily help in using the toilet and getting out of bed; there are tasks related to mobility, to eating and to the basic administration of medicines. This is a major challenge to service institutions and easily leads to differentiation. One option is to start from the ground up - to look at individuals and what they need. If we start from people and everyday life situations, it is not possible to draw strict demarcation lines between health and social services or between personal care and housing chores, as is increasingly done due to the professionalisation, specialisation and fragmentation of service systems (to achieve greater cost efficiency and effectiveness).

The complementarity argument refers to a slightly different aspect. 
There are usually strong interdependencies, for instance between informal and formal care, unpaid and paid care, municipal and voluntary work, and so on. Social services often function as mechanisms that foster interdependencies between social policy systems, different welfare agencies and sectors, and make it possible for people to obtain different sources of help and to move between them in a flexible way. This kind of plasticity should be taken as a major strength of care and other social services. There is a need for social policy measures and mechanisms that integrate separate policy fields and everyday sectors and combine different 'capitals' to be mobilised in meeting life-course risks. To some extent this is self-evident: parents take care of children part of the time, even though children are in organised daycare. Partners and spouses still have a more or less significant responsibility for caring activities, even if there are services provided at home for the person who needs care. There is, however, a big difference if these intersections are understood as complementary instead of substituting each other (see 'policy options' by Martinelli, Chapter 19, in this volume).

Complexity and complementarity are features that make social services vulnerable in political terms and the object of continuous redefinitions, rescaling and cuts. As already stated, care services for older people are often the first targets of cuts. The diminishing of these services can be done through tightening access criteria (to reduce coverage rates), increasing copayments and user fees (to lower costs) or lowering the quality of service (to accelerate exit or non-use). As long as the overall status of social services is much weaker than the status of mainstream welfare services like schools and hospitals, they remain at the margin of social policies. Flexibility, plasticity and the everydayness of social services - however important they are as value markers - can easily be turned against these services. Politicians often use the language of the subsidiarity and exchangeability of social service functions when 'justifying their lower status' among welfare services. The status also remains low because some elements of care services can be produced by households: cleaning, food preparation, shopping and socialising. Decision-makers readily think that these functions belong to the sphere of relatives or charities and not public authorities.

Social services should thus be defined as broadly as possible to bring unity and integration to the diversity of meeting people's care needs. Social services need to remain somewhat unspecified and flexible in the same way that our daily lives are a little chaotic. There are highly professionalised and specialised segments of social services, for instance, services for disabled people or the young unemployed. But despite this specialisation, it is important to underline the 'integrative' dimension of service provision. This relates to the complementary role of social policy functions in 
responding to life-course risks. Unemployment benefits are necessary for daily living, but they do not get a person back into work or offer a decent life. Pensions may increase the independence of older people if their level is high enough, but they do not guarantee that care needs are met.

\section{CONCLUSIONS}

This book provides ample evidence for the argument that social services are a social policy field with a growing academic and political importance. It also raises many important questions about how the social service system should be developed further, what can be learned from the experiences of other countries, and what the main similarities and differences are in social service provision. It is extremely important to know where we come from, where we are now and where we are possibly heading. The main aim of this chapter was to look at some common features typical of social (care) services, on the basis of the very rich empirical evidence gathered in the course of the COST Action IS1102 SO.S. COHESION - Social services, welfare states and places, with particular attention to services for older people.

Care services are a fairly recent concept, referring to such personal social services that aim at meeting care needs that are most extensive at the beginning and at the end of an individual's life course (Anttonen and Zechner, 2011). The ageing populations in the developed world have brought care services for older people to the fore in social research and social politics. The overall developments of modernisation and individualisation have accelerated the socialisation of care. The entry of women into paid labour has more or less radically changed the norm that families should bear the main responsibility for caring for older people. Indeed, the degree of universality of care services is a good indicator of both gender equality and strength of commitment to the social service state in different countries.

Our main conclusions are that social services are closely related to lifecycle risks. We can expect that 'life-course welfare' will become increasingly important due to the ageing of societies and other transformations, such as extensive youth unemployment, the social investment turn in social policies and the increase in social service research and knowledge. To some extent, it is possible to agree that 'social services' currently still lie at the margin of welfare state research, but they are moving towards the centre. Social service systems have followed some general trends in their development, but they also are rooted more or less deeply in specific national histories and circumstances. Thus, we cannot underestimate the diversity of social service systems, the different degree to which formal social services are accessible and affordable for citizens in different countries or the amount 
of choice that people can exercise in opting in or out of publicly funded service systems or informal dependencies. There are different regimes or models that seem to be fairly path-dependent: (1) the family-centric model in Southern and partly also in Eastern European countries; (2) the marketised welfare mix model in the UK; (3) the social insurance model of Germany and Austria; and (4) the public service model in the Nordic countries. These models can still be identified, but there is also a blurring of boundaries (see Martinelli, Chapter 19, in this volume).

Care services for older people are rarely universal entitlements when it comes to the coverage, access and funding of these benefits. This is connected to the fact that care services are not focused strictly on health or housing, for instance, but the range is very broad. Therefore, these services and their outcomes are necessarily to some extent multi-positioned. This explains the complexity and complementarity of these services. They are closely related to other welfare services and are thus 'integrative' by nature. Complementarity means that caring is often based on multiple sources of help and this should be a strength, but it is also a weakness, as complementarity easily turns into substitution, whereby families must take on more responsibility when services are curtailed. In conclusion, social services form a very interesting object of research: their specificities represent a strength, but also a major weakness. This dilemma cannot easily be solved until the ambiguity of caring situations is unravelled.

\section{REFERENCES}

Anttonen, A. and J. Sipilä (1996), 'European social care services: is it possible to identify models?', European Journal of Social Policy, 6 (2), 87-100.

Anttonen, A. and M. Zechner (2011), 'Theorising care and care work', in B. PfauEffinger and T. Rostgaard (eds), Care, Work and Welfare in Europe, Basingstoke: Palgrave Macmillan, pp. 15-34.

Anttonen, A., J. Baldock and J. Sipilä (eds) (2003), The Young, the Old and the State. Social Care in Five Industrial Nations, Cheltenham, UK and Northampton, MA, USA: Edward Elgar Publishing.

Anttonen, A., L. Häikiö and K. Stefánsson (eds) (2012), Welfare State, Universalism and Diversity, Cheltenham, UK and Northampton, MA, USA: Edward Elgar Publishing.

Anttonen, A., L. Häikiö, K. Stefánsson and J. Sipilä (2012), 'Universalism and the challenge of diversity', in A. Anttonen, L. Häikiö and K. Stefánsson (eds), Welfare State, Universalism and Diversity, Cheltenham, UK and Northampton, MA, USA: Edward Elgar Publishing, pp. 1-15.

Bagnato, A., S. Barillà and F. Martinelli (2014), 'The public supply of care for older people in Reggio Calabria. The impact of the crisis on a long-standing deficit', presentation at the COST Action IS1102 Workshop, Ekonomickà Univerzita, Bratislava, 3-7 November. 
Béland, D., P. Blomqvist, J. Goul Andersen, J. Palme and A. Waddan (2014), 'The universal decline of universality? Social policy change in Canada, Denmark, Sweden and the UK', Social Policy \& Administration, 48 (7), 739-56.

Bode, I. (2013), 'The changing governance of domiciliary elderly care in Germany', unpublished paper presented at the COST Action IS1102 Workshop, Dunarea de Jos University, Galati, 5-8 November.

Bouget, D., H. Frazer, E. Marlier, S. Sabato and B. Vanhercke (2015), Social Investment in Europe. A Study of National Policies, Brussels: European Commission.

Dahl, R. (1989), Democracy and its Critics, New Haven: Yale University Press.

Deusdad, B. (2013), 'Regulatory trajectory and current organisational framework of social services and social care', COST Action IS1102 Working Papers, no. 1, accessed at http://www.cost-is1102-cohesion.unirc.it/docs/working-papers/wg1. spain-catalonia-social-services-b.deusdad.pdf.

Ferragina, E. and M. Seeleib-Kaiser (2015), 'Determinants of a silent (r)evolution: understanding the expansion of family policy in rich OECD countries', Social Politics, 22 (1), 1-37.

Hemerijck, A. (2013), Changing Welfare States, Oxford: Oxford University Press.

Holmlund, P. (2016), 'NPM I välfärdsstaten: hotas universalism?', Statsvetenskpalig Tidskrift, 111 (1), 39-67.

Jensen, C. (2010), 'The forgotten half: analysing the politics of welfare services', International Journal of Social Welfare, 20 (4), 404-12.

Jenson, J. (2011), 'Diffusing ideas for after neoliberalism. The social investment perspective in Europe and Latin America', Global Social Policy, 10 (1), 59-84.

Kubalčíková, K. and J. Havlíková (2013), 'The current development of social services in the care of the older people: deinstitutionalization and/or marketization?', unpublished paper presented at the COST Action IS1102 Workshop, Dunarea de Jos University, Galati, 5-8 November.

Pace, C. and D. Bezzina (2012), 'Trends in the provision and financing of long term care in residence and in the community in Malta for elderly, persons with mental health problems and with disability: a case study and a theoretical exploration', unpublished paper presented at the COST Action IS1102 Workshop, Rovira i Virgili University, Tarragona, 17-19 October.

Pfau-Effinger, B. and B. Geissler (eds) (2005), Care and Social Integration in European Societies, Bristol: Policy Press.

Ranci, C. and E. Pavolini (eds) (2013), Reforms in Long-Term Care Policies in Europe. Investigating Institutional Change and Social Impacts, New York: Springer.

Seeleib-Kaiser, M. (ed.) (2008), Welfare State Transformations. Comparative Perspective, Basingstoke: Palgrave Macmillan.

Stoy, V. (2014), 'Worlds of welfare services: from discovery to exploration', Social Policy \& Administration, 48 (3), 343-60.

Vabø, M. and M. Szebehely (2012), 'A caring state for all older people', in A. Anttonen, L. Häikiö and K. Stefansson (eds), Welfare State, Universalism and Diversity, Cheltenham, UK and Northampton, MA, USA: Edward Elgar Publishing, pp. 121-43.

Vaiou, D. and D. Siatitsa (2013), 'Current organisational framework of elderly care services', COST Action IS1102 Working Papers, no. 2, accessed at http://www. cost-is1102-cohesion.unirc.it/docs/working-papers/wg1.greece-care-for-older-peo ple-d.vaiou-and-d.siatitsa.pdf. 
Verbeek, H., E. van Rossum, S.M.G. Zwakhalen, G.I.J.M. Kempen and J.P.H. Hamers (2009), 'Small, homelike care environments for older people with dementia: a literature review', International Psychogeriatrics, 21 (2), 252-64.

Yeandle, S. (2014), 'Reconfiguring services for older people living at home in Leeds, UK: how have services changed?', unpublished paper presented at the COST Action IS1102 Workshop, University of Tampere, Tampere, 2-6 June; now published as S. Yeandle (2016), 'From provider to enabler of care? Reconfiguring local authority support for older people and carers in Leeds, 2008 to 2013', Journal of Social Service Research, 42 (2), 218-32. 